\title{
Factors Associated with COVID-19 Infection, Hospitalization and Death in New York City Neighborhoods
}

Anna Gu MD, PhD; Hira Shafeeq, PharmD, BCPS; Ting Chen PharmD Candidate; Preety Gadhoke, PhD, MPH

St. John's University, Queens, NY

\begin{abstract}
Background: A key to an effective Coronavirus 2019 (COVID-19) Community Intervention is to understand populations who are most vulnerable to it. We aimed at evaluating characteristics of New York City communities where rates of confirmed COVID-19 cases were particularly high.

Methods: The study outcomes - neighborhood-specific confirmed COVID-19 cases, positive tests, and COVID-19 attributable deaths were calculated using data extracted from the New York City government health website, which were linked to results from Community Health Survey. Distributions of study outcomes across New York City community districts and their associations with neighborhood characteristics were examined using Jonckheere-Terpstra tests.

Results: As of May 21, 2010, rates of confirmed cases ranged from 0.8\% (Greenwich Village and Soho) to 3.9\% (Jackson Heights), and the rates of attributable death from to $0.6 \%$ (Greenwich Village and Soho) to $4.2 \%$ (Coney Island). Higher percentages of black, Hispanic and foreign-born populations, lower educational attainment, poverty, lack of health insurance, and suboptimal quality of health care were all factors found to be correlated with increased rates of confirmed COVID-19 cases.

Conclusions: The epidemiology of COVID-19 exhibited great variations among neighborhoods in New York City. Community interventions aimed at COVID-19 prevention and mitigation should place high priorities in areas with large populations of blacks and Hispanics and economically disadvantages areas.
\end{abstract}

Keywords: COVID-19, race and ethnicity, epidemiology, quality and outcomes

\section{Introduction}

Over the course of the coronavirus (COVID-19) pandemic, New York City emerged as an epicenter in the United States. Comprised of five boroughs: The Bronx, Brooklyn, Manhattan, Queens and Staten Island, New York City is the nation's largest and most densely populated city with a highly diverse population. Patterns of environmental, health, socioeconomic, and racial disparities associated with COVID-19 outcomes are becoming evident. A recent JAMA published research letter briefly outlined substantial variations in COVID-19 hospitalizations and deaths across New York City Boroughs (Wadhera et al., 2020), which necessitated further studies for more detailed data. Health-care systems across the US have reported disproportionately high COVID-19 related hospitalization rates among black and Hispanic patients (Garg S. 2020, Gold JA 2020, Price-Haywood 2020). Community based factors such as healthcare access and quality, health literacy and underlying health conditions are likely to have an impact on COVID-19 susceptibility. (CDC. COVID-19 in Racial and Ethnic Minority Groups.2020)

Corresponding author: Anna Gu, MD PhD

Department of Pharmacy Administration and Public Health

St. John's University

8000 Utopia Parkway, Queens, NY 11439

Phone: 718990 8263; Fax: 7189906316

E-mail: gus@stjohns.edu
Studies reveal that living in economically disadvantaged neighborhoods is associated with high rates of unemployment, greater need for public assistance, lower educational attainment, and suboptimal health outcomes (Rosenbaum and Friedman, 2004, Kennedy 2013, Diez-Roux and Mair, 2010, Warnecke et al., 2008). The cumulative effect of these social and economical inequalities may result in a higher disease burden during a pandemic. Higher educational attainment leads to greater control of one's life through improved access to resources and self-determination (Regidor et al. 2002). Lower educational attainment among blacks and Hispanics, therefore, can have dire consequences, in terms of health literacy, disease awareness, and healthcare access and quality (Richardus and Kunst, 2001, Sun et al. 2013). Moreover, significant racial gaps persists in access to social services and public assistance, including racial/ethnic immigrants (Fomby and Cherlin, 2004).

Efforts to address and reduce health disparities are needed through interdisciplinary, multi-level approach across public health, clinical, and basic sciences (Jones, 2010, Warnecke et al., 2008). We aimed to evaluate the associations between neighborhood-level characteristics and rates of COVID-19 cases and attributable mortality in New York City, the epicenter of the pandemic in the US. 


\section{Methods}

\section{Study Subjects and outcome measures}

The outcome measures include rates of COVID-19 confirmed cases, attributable death rates, and positive test rates. Rates of confirmed cases were calculated using number of reported confirmed cases divided by total population size. Positive test rates were defined as the ratio of positive tests to total number of tests. Attributable death rates were calculated as number of reported COVID-19 related deaths divided by total number of confirmed cases at the same time. Since April 2020, daily updated data related to COVID-19 outcomes (rates of confirmed cases, positive tests, and attributable death) by modified ZIP code tabulation areas (ZCTA) were accessible to the public via the website of NYC Department of Health and Mental Hygiene (NYC DHMH). Each of the 177 Modified ZCTAs was mapped into NYC United Hospital Fund (UHF) neighborhoods and neighborhood-specific rates of the COVID19 outcome measures were calculated with population sizes of modified ZCTAs as weights.

\section{Independent variables}

Neighborhood level demographic and socioeconomic characteristics, as well as health care quality and outcome measures were obtained from Community Health Profiles based on New York City Community Health Survey (NYC CHS) 2018. The geographic distribution and survey results of the communities can be found via the website of New York City community health profiles (https://a816health.nyc.gov/hdi/profiles/).

Sociodemographic characteristics: age, gender, and racialethnic distributions, percentage of foreign-born residents, percentage of residents with a college degree (among adults $\geq 25$ years), and poverty rate.

Healthcare access and outcomes: percentage of adults without health insurance, percentages of adults with obesity, diabetes mellitus and hypertension, premature death (number of death before age 65 per 100,000 people), avoidable hospitalizations (per 100,000 adults) and life expectancy.

\section{Statistical methods}

We used descriptive statistics to examine the distributions of and potential associations between dependent and independent variables. Outcomes measures were compared across communities categorized by quartiles of distributions of independent variables, using Jonckheere-Terpstra tests, a nonparametric, rank-based trend test for ordered alternatives. All statistical analyses were conducted using SAS (version 9.4.3, SAS Institute Inc., Cary, NC, USA).

\section{Results}

As of late May the total number of confirmed cases in New York City was 225,915, corresponding to an overall case rate of $26.9 \%$. Remarkable variations in COVID-19 related outcomes were observed in the 59 community districts in New York City.
Lower rates were most frequently observed in the borough of Manhattan. Rates of confirmed COVID-19 cases (per 1,000 population) ranged from 8.2 (Greenwich Village and Soho, Manhattan) to 39.4 (Jackson Heights, Queens), with a median of 22.3 (Flatbush and Midwood, Brooklyn). The lowest COVID19 related death rate ( 0.58 per 1,000 population) was also observed in Greenwich and Soho, and the highest 4.2\%o (Coney Island). Stuyvesant Town and Turtle Bay (Manhattan) had the lowest positive test rate (18.4\%) and the highest in Elmhurst and Corona, Queens (44.9\%). As expected, neighborhoods in New York City were highly heterogeneous in terms of racial and ethnic distributions, socioeconomic status, and healthcare access and outcomes. For example, the proportions of blacks ranged from $1 \%$ to $88 \%$ and poverty rates $7 \%$ to $34 \%$. (Table 1b).

Sociodemographic characteristics and health outcomes in New York City communities with high rates (highest 25\%) of confirmed COVID-19 cases are presented in Table 2. In general, communities with highest rates of infection were disproportionally represented in Queens and The Bronx. Most of these communities also had rates of COVID-19 related death and positive test ranking in the highest $25 \%$ of all New York City communities. Residents of Hispanic or black origin were disproportionately represented in these neighborhoods. The 15 communities with the highest rates of COVID-19 confirmed cases were also exclusively represented in the highest $25 \%$ for proportions of residents ( $\geq 25$ years) without a college degree. Consistent with an overall lower educational attainment, lower socioeconomic status and multiple comorbidities were particularly prevalent in these communities. (Table 2).

The rates of all three study outcomes increased consistently in communities with high percentages of Hispanic, black, or foreign-born populations, poverty, suboptimal educational attainment, and uninsured populations. For example, rates of COVID-19 confirmed cases decreased by $50 \%$ and death rates more than $50 \%$ from communities where percentages of adults with a college degree ranked in the lowest $25 \%$ to the highest $25 \%$ (confirmed cases: from $27.67 \%$ to $13.84 \%$ o, Ptrend $<0.001$; deaths: from $2.27 \%$ to $1.11 \%$, Ptrend $<0.001$ ). High COVID-19 rates also echoed suboptimal outcomes in health care quality. Pronounced elevations in COVID-19 rates were coupled with increased rates in obesity, diabetes, and hypertension, lack of health insurance, as well as high premature mortality and avoidable hospitalizations in the community. (Table 3 and Figures 1-3).

\section{Discussion}

The study findings highlight a high degree of disparities in racial and ethnic distribution, socioeconomic status, healthcare access, and health outcomes in New York City neighborhoods. The coexistence of highest rates of confirmed COVID-19 cases and the greatest socioeconomic inequities, such as the highest rates of residents without a college degree, were reported in 15 neighborhoods in Queens and the Bronx boroughs. Consistent 
with an overall lower educational attainment, poverty and poor health outcomes were highly prevalent in these neighborhoods. Elevations in COVID-19 rates correlated with high prevalence of obesity, diabetes, and hypertension, and excessive premature mortality and avoidable hospitalizations also present in these communities. The study results and their implications are generalizable to other metropolitan areas in the US.

The study corroborates with the literature reporting "racial, ethnic, and neighborhood-level inequalities in health and healthcare are a long-standing problem in the United States" (Gusmano et al. 2017; 187). Furthermore, persistent inequalities of neighborhoods, including income inequality, racial segregation, and concentrated poverty, remain barriers to reducing and eliminating disparities in access to healthcare and, ultimately, achieving health equity. It is necessary to not only identify these differences across neighborhoods that may make life and health "hostile," but also to implement informed tailored policies and programs to achieve health equity for blacks and Hispanic members of urban communities (Sandel et al., 2016; Schulz et al., 2002). Healthcare literacy is of fundamental importance in the prevention, mitigation and containment of COVID-19. More information is needed pertaining to education and its impact on access to accurate information during an ongoing pandemic. Additionally, ethnic and cultural factors may lead to differences in communities obtaining and following preventive measures. Access to accurate and timely information is imperative for implementation of preventative measures. Considerations should be made for language as a barrier that may reduce health literacy in vulnerable populations, especially during a time when people are being instructed to stay home. Effective community-based interventions to stop the spread of a pandemic must take into account the city's most vulnerable populations with a deeper understanding of challenges for these populations in accessing health information. Information pertaining to the ongoing pandemic should be made available in multiple languages. Technologically savvy applications may be key for effective distribution of information and collecting real-time accurate information from differently abled and ethnically diverse members of the community. (Chan AT et al. 2020)

Social distancing has been regarded as the best intervention for reducing the spread of the current pandemic. Lowest rates for the infection and death associated with COVID-19 were reported in the borough of Manhattan, even though it is the most densely populated borough in New York City. Jackson Heights and Elmhurst/Corona were reported as neighborhoods with the greatest burden of sociodemographic and COVID-19 related disparities in Queens. These neighborhoods historically represent African-Americans who moved from the South, Harlem, and the West Indies to the South of Jamaica in Queens (QHS, 2020), the most ethnically diverse borough of New York. Jackson Heights and Elmhurst are neighborhoods that boast the highest percentage of people born outside the US and the highest rent burden in the City. Bronx neighborhoods have witnessed waves of immigrants, and also high poverty rates, lowest percentage of high school graduation and college graduates in Mott Haven, and the highest percentage of unemployment in the Bronx (Naidoo et al., 2018). Queens and the Bronx currently have the highest proportion of foreign-born populations in New York City. According to 2017 estimates, Queens has the greatest number of Asia-born $(444,215)$, Southeastern Asian-born (54,969), and Latin-American and Caribbean-born residents $(526,857)$. Queens also boasts the second highest number of South-American-born $(259,741)$ and the third highest number of African-born residents $(23,722)$. The Bronx has the highest number of African-born $(57,650)$ and third highest number of Latin-American and Caribbean-born residents $(409,381)$ (NYC Data, 2018). These sheer numbers reflect not only a rich diversity and multiculturalism but, more importantly, point towards a crucial opportunity to overcome the underlying barriers to health literacy, access to quality healthcare, and promote health behaviors among racial/ethnic immigrants.

Structural racism has limited access to quality education, healthcare services, housing, recreational facilities (for health promotion), and also induces stress and distress that can increase crime and violence in a neighborhood (Naidoo et al., 2018; William and Collins, 1995). Historically, New York City has witnessed economic stratification, racial segregation in schools, neglected needs of ethnic minority children, and discriminatory housing lending policies (Britannica, 2017). This includes inequitable neighborhood development and planning policies that have reverberated through the lifespans of children into adulthood and through generations, including: lack of access to equal education, poor quality healthcare, unfair housing, unequal employment opportunities, poor access to physical activity and nutritious foods, and lower income (Naidoo et al., 2018).

A plethora of literature suggests an association between race, ethnicity, and health as a primary function of socioeconomic status (income and education) (Lawrence, 2002). At the neighborhood-level, race-based residential discrimination and segregation among blacks and Hispanics, along with high concentrations of poverty "sustain racial patterns of healthcare delivery," where blacks and Hispanics more likely to be uninsured and face financial disadvantages with medical debt (Gusmano et al. 2017; 188). As a limitation the study is primarily descriptive due to its small sample. Nevertheless our study adds to a growing body of literature proving that race, ethnicity, socioeconomic status and educational level affects how people interact with the healthcare system which can have a profound impact on health care outcomes.

In closing, socioeconomic, racial, and health inequities and inequalities in New York City and other metropolitan areas in the nation can be mitigated with multilevel interventions and 
protections against racial and ethnic injustices. Emphasis must be placed on tailoring programs and policies for large, diverse, and socially disadvantaged neighborhoods in Queens and the Bronx. Expanding social protection programs such as public healthcare insurance, as well as addressing the structural injustices such as unfair housing and rent burdens with equitable laws and programs, investing in equitable public primary school systems, welfare programs, workforce training and public health programs to raise health literacy and heath knowledge, can all help through multilevel and interdisciplinary approaches (Gusmano et al. 2017; Warnecke et al. 2018).

Subject codes: COVID-19, race and ethnicity, epidemiology, quality and outcomes

Authorship statement: The work presented here is original and has not been submitted for publication elsewhere. The authors accept responsibility for the scientific content of the manuscript.

\section{References}

Center for Disease Control and Pevention.COVID-19 in Racial and Ethnic Minority Groups.

https://www.cdc.gov/coronavirus/2019-ncov/need-extraprecautions/racial-ethnic-minorities.html (accessed 6/14/2020).

Chan AT, Brownstein JS. Putting the Public Back in Public Health - Surveying Symptoms of Covid-19. N Engl J Med. Published online June 5, 2020:NEJMp2016259

Diez-Roux, A. and C. Mair. 2010. Neighborhoods and health. Annals of the New York Academy of Sciences, 1186(1). https://doi.org/10.1111/j.1749-6632.2009.05333.x

Encyclopedia Britannica. 2017. New York City. https://www.britannica.com/place/New-York-City

Fomby, P. and A. J. Cherlin. 2004. Public assistance use among US-born children of immigrants. International Migration Review, 38(2):584-610.

Garg S, Kim L, Whitaker M, et al. Hospitalization Rates and Characteristics of Patients Hospitalized with LaboratoryConfirmed Coronavirus Disease 2019 - COVID-NET, 14 States, March 1-30, 2020. MMWR Morb Mortal Wkly Rep 2020;69:458-464.

Gold JA, Wong KK, Szablewski CM, et al. Characteristics and Clinical Outcomes of Adult Patients Hospitalized with COVID19 - Georgia, March 2020. MMWR Morb Mortal Wkly Rep 2020;69:545-550.
Goyal, P., Choic, J.J., Pinheiro, L. C., Schenck, E. J., Chen, R., Jabri, A., Horn, E. M., Martinez, F. J., et al. 2020. Clinical characteristics of Covid-19 in New York City. New England Journal of Medicine, DOI: 10.1056/NEJMc2010419.

Gusmano, M. K., Rodwin, V. G., and D. Weisz. 2017. Persistent inequalities in health and access to health services: Evidence from New York City. World Medical and Health Policy, 9:2:186205.

https://wagner.nyu.edu/files/faculty/publications/Gusmano_e t_al-2017-

World_Medical_\%26amp\%3B_Health_Policy\%20\%281\%29.pdf

Jones, C.M. 2010. The moral problem of health disparities. American Journal of Public Health. 100(Suppl. 1): S47-S51. DOI:10.2105/AJPH.2009.171181.

Kennedy, B. R. 2013. Health inequalities: promoting policy changes in utilizing transformation development by empowering African American communities in reducing health disparities. Journal of Cultural Diversity, 20(4): 155-162.

Lawrence, D. 2002. Which diseases contribute to lifeexpectancy differences between races? The Lancet. 360 (9345):1571.

Naidoo M, Traore K, Culp G, King L, Lopez C, Hinterland K, Gould LH, Gwynn RC. 2018. Community Health Profiles 2018 Map Atlas; The New York City Department of Health and Mental Hygiene.

NYC Data. 2018. Baruch Collee Zicklin School of Business. Population and Geography. New York City (NYC). Foreign-Born Population - By Country of Birth. 2017 Estimates. US Census. American Community Survey data. https://www.baruch.cuny.edu/nycdata/populationgeography/foreign-birthcountry.htm

New York City Department of Mental Health and Hygiene. (NYC). 2020. COVID-19 Data.

https://www1.nyc.gov/site/doh/covid/covid-19-data.page

Queens Historical Society. 2020. Queens History Timeline. https://queenshistoricalsociety.org/queens-history-timeline/

Regidor, E., de Mateo, S., Calle, M. E., and V. Dominguez. 2002. Education level and mortality from infectious diseases. Journal of Epidemiology and Community Health, 56(9):682. DOI:10.1136/jech.56.9.682

Richardus, J. H., and A. E. Kunst. 2001. Black-White differences in infectious disease mortality in the United States. American Journal of Public Health, 91(8):1251. 
Rosenbaum, E., and S. Friedman. 2004. Generational patterns of home ownership and housing quality among Racial/Ethnic groups in New York City, 1999. International Migration Review, 38(4): 1492-1533.

Sandel, M., Faugno, E., Mingo, A, Cannon, J., Byrd, K, Garcia, D. A. et al. 2016. Neighborhood-level interventions to improve childhood opportunity and lift children out of poverty.

Academic Pediatrics, 16(3):S128-135.

Schultz, A. J., Williams, D. R., Israel, B. A., and L. B. Lempert. 2002. Racial and spatial relations as fundamental determinants of health in Detroit. Millbank Quarterly, 80(4):677-705.

Sun, X., Shi, Y., Zeng, Q. Wang, Y. and W. Du. 2013. Determinants of health literacy and health behavior regarding infectious respiratory diseases: a pathway model. BMC Public Health, 13:261. DOI:10.1186/1471-2458-13-261.

Wadhera, R. K., Wadhera, P., Gaba, P., Figueroa, J. F., Maddox, K. E. J., Yeh, R. W., and C. Shen. 2020. Variation in COVID-19 hospitalizations and deaths across New York City boroughs. Journal of American Medical Association, e207197. doi: 10.1001/jama.2020.7197 [Epub ahead of print]

Warnecke, R.B., Oh, A. Breen, N. Gehlert, S., Paskett, E. et al. 2018. Approaching health disparities from a population perspective: The National Institutes of Health Centers for Population Health and Health Disparities. American Journal of Public Health, 98(9):1608-1615. 
Table 1a. Univariate distributions of COVID-19 outcomes in New York City communities, May, 2020

\begin{tabular}{lcccccc}
\hline & Min & $25 \%$ & $50 \%$ & $75 \%$ & Max & Overall \\
\hline COVID-19 related outcomes & & & & & & \\
$\quad$ Case rate, \%o & 8.2 & 15.8 & 22.3 & 27.9 & 39.4 & $26.9^{*}$ \\
Positive rate, \% & 18.4 & 29.6 & 34.7 & 37.2 & 44.9 & $30.0^{*}$ \\
Death rate, \% & 0.58 & 1.29 & 1.94 & 2.46 & 4.20 & $1.99^{*}$ \\
\hline
\end{tabular}

* Calculated based on total number of confirmed cases $(\mathrm{N}=225,915)$, population size $(\mathrm{N}=8,394,355)$, total tests $(\mathrm{N}=752,017)$ and total number of related death $(\mathrm{N}=16,739)$; definitions of the outcomes were described in the "Methods" section.

Table 1b. Univariate distributions of sociodemographic characteristics, health outcomes, and COVID-19 outcomes in New York City communities.

\begin{tabular}{|c|c|c|c|c|c|}
\hline & Minimum & $\begin{array}{c}25^{\text {th }} \\
\text { Percentile }\end{array}$ & $\begin{array}{c}50^{\text {th }} \\
\text { Percentile }\end{array}$ & $\begin{array}{c}75^{\text {th }} \\
\text { Percentile }\end{array}$ & Maximum \\
\hline \multicolumn{6}{|l|}{ COVID-19 related outcomes } \\
\hline Case rate, $\%$ & 8.2 & 15.8 & 22.3 & 27.9 & 39.4 \\
\hline Positive rate, $\%$ & 18.4 & 29.6 & 34.7 & 37.2 & 44.9 \\
\hline Death rate, $\%$ & 0.58 & 1.29 & 1.94 & 2.46 & 4.20 \\
\hline \multicolumn{6}{|l|}{ Sociodemographic characteristics } \\
\hline Median age, $\mathrm{y}$ & 28.9 & 32.8 & 35.5 & 39.0 & 45.4 \\
\hline Male, $\%$ & 43.0 & 45.6 & 47.2 & 48.6 & 53.5 \\
\hline Black, \% & 1.0 & 3.0 & 13.0 & 31.0 & 88.0 \\
\hline Hispanic, $\%$ & 7.0 & 13.0 & 22.0 & 45.0 & 76.0 \\
\hline White, $\%$ & 1.0 & 9.0 & 26.0 & 56.0 & 84.0 \\
\hline Foreign born, $\%$ & 15.0 & 26.0 & 35.0 & 44.0 & 63.0 \\
\hline Without college degree, $\% *$ & 16.0 & 29.0 & 38.0 & 49.0 & 84.0 \\
\hline Poverty, \% & 7.0 & 15.0 & 21.0 & 25.0 & 34.0 \\
\hline \multicolumn{6}{|l|}{ Health outcome } \\
\hline Uninsured, $\% \dagger$ & 3.0 & 8.0 & 12.0 & 14.0 & 28.0 \\
\hline Obesity, $\% \dagger$ & 4.0 & 20.0 & 25.0 & 32.0 & 42.0 \\
\hline Diabetes, $\% \dagger$ & 3.0 & 9.0 & 13.0 & 15.0 & 22.0 \\
\hline Hypertension, $\% \dagger$ & 15.0 & 23.0 & 28.0 & 34.0 & 42.0 \\
\hline Avoidable hospitalization $\sharp$ & 426 & 834 & 1250 & 1786 & 3138 \\
\hline Premature death§ & 78.2 & 122.9 & 167.4 & 215.5 & 356.1 \\
\hline Life expectancy, y & 75.1 & 79.7 & 81.4 & 83.9 & 85.9 \\
\hline
\end{tabular}

* Among adults aged 25 years and older, $\dagger$ Among adults; $\$$ Per 100,000 adults;

$\S$ Rate of death before age 65 per 100,000 people (number of deaths). 
Table 2. Sociodemographic characteristics and health outcomes in New York City communities with high rates of confirmed COVID-19 cases, May 2020

\begin{tabular}{|c|c|c|c|c|c|c|c|c|c|c|c|c|c|c|c|c|c|c|}
\hline \begin{tabular}{|c|}
\multicolumn{2}{|c|}{ Neighborhood } \\
Premature Avoidable
\end{tabular} & Borough & $\begin{array}{l}\text { Case } \\
\text { rate }\end{array}$ & \begin{tabular}{|c|} 
Positive \\
rate
\end{tabular} & $\begin{array}{l}\text { Death } \\
\text { rate }\end{array}$ & $\begin{array}{l}\text { Median } \\
\text { age }\end{array}$ & $\begin{array}{c}\text { Male } \\
\%\end{array}$ & $\begin{array}{c}\text { Black } \\
\%\end{array}$ & $\begin{array}{c}\text { Hispanic } \\
\%\end{array}$ & $\begin{array}{c}\text { White } \\
\%\end{array}$ & $\begin{array}{c}\text { Foreign } \\
\text { born } \\
\%\end{array}$ & \begin{tabular}{|c|} 
Without \\
college \\
degree \%
\end{tabular} & $\begin{array}{c}\text { Poverty } \\
\%\end{array}$ & $\begin{array}{c}\text { Uninsured } \\
\%\end{array}$ & $\begin{array}{c}\text { Obesity } \\
\%\end{array}$ & $\begin{array}{c}\text { Diabetes } \\
\%\end{array}$ & $\begin{array}{c}\text { Hyper- } \\
\text { tension } \\
\%\end{array}$ & death† & Hospitalization§ \\
\hline Jackson Heights & Queens & 39.4 & $44.3^{*}$ & $3.2^{*}$ & 35.9 & 53.5 & 6 & $64 *$ & 11 & $60 *$ & $73 *$ & $25 *$ & $28 *$ & 20 & 13 & 29 & 120.9 & 869 \\
\hline Elmhurst and Corona & Queens & 36.0 & $44.9 *$ & $3.1^{*}$ & 32.8 & 52.1 & 5 & $51^{*}$ & 6 & $63^{*}$ & $72^{*}$ & $27^{*}$ & $25 *$ & 23 & 14 & 27 & 105.2 & 892 \\
\hline Riverdale and Fieldston & Bronx & 35.8 & 25.5 & $3.1^{*}$ & $44.3^{*}$ & 45.0 & 12 & $47^{*}$ & 34 & 34 & $55^{*}$ & 15 & 8 & 24 & 12 & 28 & 170.4 & 1250 \\
\hline Williamsbridge and Baychester & Bronx & 35.4 & $39.9 *$ & $3.2^{*}$ & 36.2 & 45.5 & $65 *$ & 25 & 6 & 40 & $68^{*}$ & 23 & 8 & 30 & 14 & $39 *$ & 202.3 & $1891^{*}$ \\
\hline Throggs Neck and Co-op City & Bronx & 35.1 & 33.2 & $2.5^{*}$ & $43.1^{*}$ & 45.2 & 23 & 40 & 30 & 21 & $66^{*}$ & 14 & 7 & 24 & 13 & $37 *$ & 183.3 & 1185 \\
\hline Queens Village & Queens & 32.1 & $41.0^{*}$ & 1.9 & $39.4^{*}$ & 46.7 & $56 *$ & 12 & 12 & 42 & $62 *$ & 13 & 11 & 27 & 14 & $37 *$ & 117.3 & 1084 \\
\hline Morris Park and Bronxdale & Bronx & 31.7 & $39.2 *$ & $2.7^{*}$ & 32.8 & 47.0 & 21 & $45 *$ & 24 & 35 & $68^{*}$ & 21 & 12 & $32 *$ & 14 & 31 & 206.9 & 1613 \\
\hline Rockaway and Broad Channel & Queens & 31.3 & $37.6 *$ & $3.8^{*}$ & 35.4 & 47.1 & $40 *$ & 22 & 33 & 26 & $65^{*}$ & 18 & 11 & $32 *$ & $15 *$ & $34 *$ & $269.3^{*}$ & 1345 \\
\hline Mott Haven and Melrose & Bronx & 29.9 & 36.1 & $2.6^{*}$ & 30.6 & 46.3 & 24 & $73^{*}$ & 1 & 30 & $84^{*}$ & $29 *$ & $14^{*}$ & $42 *$ & $20 *$ & $38^{*}$ & $302 *$ & $3138^{*}$ \\
\hline Parkchester and Soundview & Bronx & 29.9 & 36.7 & 2.2 & 34.3 & 47.0 & 30 & $59 *$ & 2 & 32 & $77^{*}$ & $26 *$ & 6 & $32 *$ & $16^{*}$ & $34^{*}$ & 195.5 & 1631 \\
\hline St George and Stapleton & $\begin{array}{l}\text { Staten } \\
\text { Island }\end{array}$ & 29.7 & 34.7 & 2.1 & 35.5 & $\begin{array}{l}48.6 \\
*\end{array}$ & 22 & 30 & 38 & 24 & $63 *$ & 21 & 12 & 24 & 9 & 26 & $227.1^{*}$ & 1308 \\
\hline Highbridge and Concourse & Bronx & 29.0 & $37.5^{*}$ & 2.0 & 30.2 & 47.0 & $31^{*}$ & $65^{*}$ & 1 & 42 & $79 *$ & $32 *$ & 13 & $34^{*}$ & $17^{*}$ & $42^{*}$ & $249.2^{*}$ & $2307^{*}$ \\
\hline Hunts Point and Longwood & Bronx & 28.6 & $39.4^{*}$ & $2.7^{*}$ & 29.0 & 47.8 & 21 & $76^{*}$ & 1 & 30 & $84^{*}$ & $29 *$ & $14^{*}$ & $42^{*}$ & $20^{*}$ & $38^{*}$ & $261.6^{*}$ & $2709^{*}$ \\
\hline South Beach and Willowbrook & $\begin{array}{l}\text { Staten } \\
\text { Island }\end{array}$ & 28.0 & 33.4 & 1.8 & $40.4^{*}$ & 48.0 & 3 & 14 & 68 & 27 & $60 *$ & 14 & 4 & 25 & 6 & 27 & 168.3 & 958 \\
\hline Fordham and University & Bronx & 27.9 & $38.3^{*}$ & 1.8 & 29.8 & 47.3 & 27 & 69* & 1 & 42 & $80 *$ & $34 *$ & $14^{*}$ & $34 *$ & $16^{*}$ & $37^{*}$ & $241.2^{*}$ & $2573^{*}$ \\
\hline
\end{tabular}

* Ranked among the highest 25\% percentiles of all New York City Communities; tRate of death before age 65 per 100,000 people (number of deaths); §per 100,000 adults.

¥ Data in race/ethnicity, education, foreign-born status, poverty, health insurance coverage, and health outcomes are from New York City Community Health Profiles 2018. 
Table 3. Rates of COVID-19 confirmed cases, positive tests, and deaths among New York City communities categorized by sociodemographic characteristics and health outcome measures.

\begin{tabular}{|c|c|c|c|c|c|c|c|c|c|c|c|c|c|c|c|}
\hline \multirow{2}{*}{ Characteristics } & \multicolumn{5}{|c|}{ Case rate, $\%$ o } & \multicolumn{5}{|c|}{ Positive test rate, $\%$} & \multicolumn{5}{|c|}{ Death rate, \%o } \\
\hline & Q1 & Q2 & Q3 & Q4 & $P_{\text {trend }}$ & Q1 & Q2 & Q3 & Q4 & $P_{\text {trend }}$ & Q1 & Q2 & Q3 & Q4 & $P_{\text {trend }}$ \\
\hline Median age & 23.20 & 22.18 & 23.23 & 20.16 & 0.45 & 34.4 & 35.0 & 35.4 & 31.0 & 0.07 & 1.96 & 2.03 & 1.89 & 1.76 & 0.30 \\
\hline Male, \% & 21.40 & 23.82 & 21.20 & 22.45 & 0.07 & 32.5 & 35.5 & 34.2 & 33.6 & 0.24 & 2.06 & 2.09 & 1.79 & 1.71 & $<0.001$ \\
\hline Black, \% & 18.75 & 20.35 & 25.58 & 24.94 & $<0.01$ & 30.6 & 33.2 & 35.3 & 37.3 & $<0.001$ & 1.57 & 1.75 & 2.08 & 2.31 & $<0.001$ \\
\hline Hispanic, \% & 19.61 & 19.88 & 22.42 & 27.50 & $<0.001$ & 30.8 & 33.6 & 34.4 & 37.2 & $<0.01$ & 1.62 & 1.91 & 1.83 & 2.32 & $<0.01$ \\
\hline White, \% & 27.04 & 23.06 & 20.85 & 16.99 & $<0.001$ & 37.6 & 37.1 & 32.8 & 27.4 & $<0.001$ & 2.30 & 2.09 & 1.86 & 1.31 & $<0.001$ \\
\hline Foreign born, \% & 17.81 & 22.77 & 24.31 & 24.01 & 0.03 & 28.5 & 33.2 & 36.6 & 37.8 & $<0.001$ & 1.48 & 1.96 & 1.98 & 2.24 & $<0.01$ \\
\hline College graduate, $\%$ & 27.67 & 24.37 & 20.59 & 13.84 & $<0.001$ & 38.2 & 35.3 & 32.9 & 25.9 & $<0.001$ & 2.27 & 2.18 & 1.87 & 1.11 & $<0.001$ \\
\hline Poverty, \% & 17.47 & 22.15 & 22.40 & 26.95 & $<0.01$ & 28.4 & 34.4 & 36.7 & 36.4 & $<0.001$ & 1.32 & 1.94 & 2.17 & 2.22 & $<0.001$ \\
\hline Uninsured, \% & 19.73 & 21.64 & 24.26 & 24.78 & 0.07 & 30.3 & 34.1 & 36.9 & 36.4 & $<0.001$ & 1.52 & 1.99 & 2.10 & 2.17 & $<0.01$ \\
\hline Obesity, \% & 17.13 & 23.12 & 24.73 & 25.60 & $<0.001$ & 29.4 & 34.8 & 36.2 & 36.1 & $<0.001$ & 1.47 & 1.87 & 2.17 & 2.23 & $<0.001$ \\
\hline Diabetes, \% & 18.34 & 19.25 & 28.29 & 27.71 & $<0.001$ & 29.6 & 32.9 & 39.3 & 37.3 & $<0.001$ & 1.49 & 1.78 & 2.62 & 2.18 & $<0.001$ \\
\hline Hypertension, \% & 15.53 & 22.24 & 25.26 & 27.98 & $<0.001$ & 28.4 & 33.5 & 36.9 & 37.4 & $<0.001$ & 1.29 & 1.88 & 2.36 & 2.29 & $<0.001$ \\
\hline $\begin{array}{l}\text { Premature death } \\
\text { Avoidable }\end{array}$ & 19.51 & 20.69 & 24.54 & 24.87 & $<0.01$ & 32.4 & 32.8 & 35.4 & 35.7 & 0.01 & 1.67 & 1.68 & 2.15 & 2.23 & $<0.001$ \\
\hline hospitalization & 15.85 & 24.14 & 24.10 & 24.34 & $<0.01$ & 28.2 & 34.9 & 35.9 & 35.8 & $<0.01$ & 1.33 & 1.92 & 2.19 & 2.17 & $<0.001$ \\
\hline Life expectancy & 25.24 & 23.60 & 20.18 & 20.21 & $<0.01$ & 35.3 & 34.5 & 34.8 & 31.8 & 0.05 & 2.28 & 1.84 & 1.78 & 1.79 & $<0.01$ \\
\hline
\end{tabular}

\footnotetext{
* Q1, Q2, Q3, Q4 denote communities in the first, second, third and forth $25 \%$ of distributions of each respective character
}

† Trend analyses were performed using Jonckheere-Terpstra tests. 

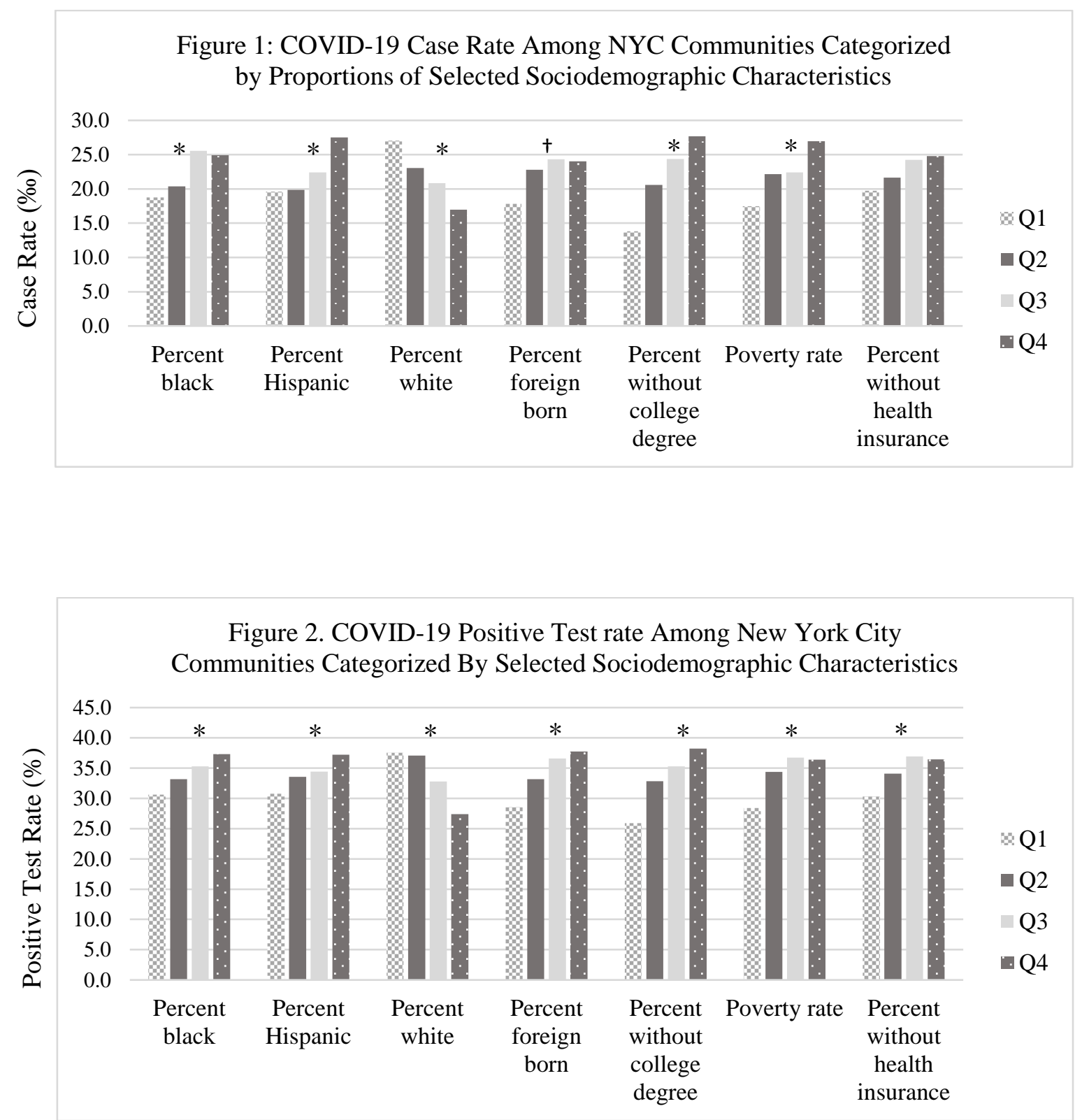